\title{
Role of Gene HLA-B51 in Bechet Syndrome (BS): A Genetic Perspective for Early Detection
}

\author{
Nanda Rachmad Putra Gofur ${ }^{1 *}$, Aisyah Rachmadani Putri Gofur ${ }^{2}$, \\ Hernalia Martadila Putri ${ }^{3}$ and Soesilaningtyas Gofur ${ }^{4}$, Rizki Nur \\ Rahman Putra Gofur ${ }^{5}$ and Mega Kahdina ${ }^{5}$ \\ ${ }^{1}$ Doctoral Program of Medical Science, Faculty of Medicine, Universitas Brawijaya, \\ Malang, Indonesia \\ ${ }^{2}$ Dental Medicine Program, Faculty of Dental Medicine, Universitas Airlangga, \\ Surabaya, Indonesia \\ ${ }^{3}$ Pakis Public Health Center, Surabaya, Indonesia \\ ${ }^{4}$ Department of Dental Promotion, Faculty of Nursing Dental Medicine - Politeknik \\ Kesehatan, Surabaya, Indonesia \\ ${ }^{5}$ Faculty of Medicine, Universitas Airlangga, Surabaya, Indonesia \\ *Corresponding Author: Nanda Rachmad Putra Gofur, Doctoral Program of \\ Medical Science, Faculty of Medicine, Universitas Brawijaya, Malang Indonesia.
}

Received: March 20, 2020

Published: May 22, 2020

(C) All rights are reserved by Nanda Rachmad

Putra Gofur., et al.

\begin{abstract}
Introduction: Behçet's disease (BD) is a rare autoimmune, and the pathogenesis is still poorly understood. Various studies have shown that genetic predisposition is a major factor in disease susceptibility especially distribution of the prevalence of HLA-B51 supports a genetic influence.

Aim: To determine the potential of the HLA-B51 gene in Bechet Syndrome.

Discussion: The observed aggregation of BD in family of patients also supports the genetic and HLA-B51 (subtype B510101) is the most strongly related genetic marker for BD. In recent years, several studies of genome-wide associations and studies of genetic polymorphisms may have an additional role in susceptibility and disease severity.

Conclusion: A comprehensive analysis of the effect of the HLA-B51 allele on the risk of developing BS further illustrates the relationship between genes playing a role in triggers and progression as one of the most potential genes.

Keywords: Behçet's Syndrome; Gene; HLA-B51
\end{abstract}

\section{Introduction}

Behçet Syndrome (BS) is an autoimmune chronic disease, a recurrence characterized by changes in vascular tissue, both arteries and veins that carry blood back to the lungs, the back of the retina of the eye, brain, joints, skin, and intestines [1]. The HLA-B51 gene is believed to be important in etiopathogenesis. The prevalence of BS is common in east Asia to the Mediterranean. The prevalence is 80 - 370 cases per 100,000 population in Turkey, 10/100,000 in Japan and 0.6/100,000 in Yorkshire. Other cases also oppose the presence of ankylosing spondylitis and psoriatic arthropathy [2].

Clinical manifestations of BS are characterized by atopic arteries in the mouth, genital mucus ulceration and eye changes (hypopyon-iritis, conjunctivitis). This lesion is an initial manifestation of up to $80 \%$ of patients in an average of 7 - 8 years [3]. Changes of buccal mucus usually begin one at a time in the form of a bed with a white layer supported by erythema. They argue with pain; they speak in terms of size and arrangement into minor ulcers $(<1$ $\mathrm{cm}$ ), mayors, and herpetiform. Besides the skin, other organs such as rheumatoid arthritis, thrombophlebitis, digestive disorders, kidney, respiratory system, CNS changes with symptoms such as psychiatric meningoencephalitis and psychogenic changes [4].

Genital lesions are similar to those in the buccal. However, they rarely recur, have greater scarring, and some determine the necrotic boundary. More lesions can complicate formation of fistulas, more in women. In women, ulcers in the vagina and large intestine can activate oligosymptomatic [5]. The area most frequently 
involved is the labia mayor. Eye disease, more common in men, affecting the retina and uvea, occurs in $30-70 \%$ of patients, causing blindness in $25 \%$ of them. It usually appears 2 - 3 years after oral and genital ulcers but may be the first manifestation of the disease in $10-20 \%$ of cases. Eye lesions usually begin in one eye and then begin in the other eye until blindness [6]. Many manifestations of BS cause previous studies using the potential role of genes and the immune system as triggers and causes of prognosis from BS, one of which is the HLA-B51 gene [7,8].

HLA-B51 is a genetic factor that is known to be most strongly associated with BS. The relationship between HLAB51 alleles and eye diseases has also been launched. This genetic contribution is also supported by a high risk of recurrence among siblings, estimated between 11.4 and 52.5 in the Turkish population [9]. The ratio of men to women is $7: 1$, but women are more against men in the severity of the sentence. BS occurs mostly between 18 to 40 years, and several cases of children are also published. After 55 years, the diagnosis of BS onset must be done very carefully, and gene HLA-B51 could be potential predictor in BS [10].

\section{Aim of the Study}

To find out the potential of the HLA-B51 gene as an early detection of Bechet Syndrome.

\section{Discussion}

Manifestations of BS can affect the whole body. The skin can be divided into papulo-pustular lesions, erythema nodular lesions, thrombophlebitis, and various skin lesions and vasculitis. Erythema nodular (EN) lesions occur in one third of patients, usually involving the lower extremities. Neurological disorders occur in 5 - $10 \%$ of patients, affecting most men. This occurs about five years after the onset of the disease mainly affecting the central nervous system and peripheral nervous system to a lesser extent. Joint involvement is reported in 45 - $60 \%$ of BS patients and includes arthralgia and monoarthritis or non-erosive, non-erosive polyarthritis. The digestive tract is affected by $3-26 \%$ of patients, varying in different populations, more common in Japan than in the Middle East and the Mediterranean. BS treatment aims to maintain remission and improve quality of life, prevent permanent damage and worsen mucocutaneous and articular diseases Local and systemic treatment in the form of fluorinated corticosteroids, sulfonate preparations (Dapsone), gammaglobulin, large doses of vitamin C. However, the etiologic of BS itself is still unknown. The HLA-B51 gene is believed to play a role in the etiopathology of BS [11].

HLA-B51, one of the antigens divided from HLA-B5, has been found to be the most accurate genetic marker for BS to date in dif- ferent ethnic groups. However, its contribution to overall BS genetic susceptibility is estimated at around 20\%. HLA-B51 often occurs in BS patients, with a range of $40-80 \%$ in ethnic groups including Turkish, European, and Asian populations from the Middle East to the East, while the lowest prevalence is $13 \%$ among white patients. in western countries. In general, the strongest correlation between BS and HLA-B51 is seen among populations with an incidence of HLA-B51 and BS with severe clinical symptoms. In a recent metaanalysis of 4,800 patients with BS and 16,289 controls from 78 independent studies, the combined odds ratio (OR) of HLA-B51/B5 allele carriers for developing BS compared with non-carriers was found to be 5.78 (95\% CI 5,00 - 6.67) [12].

There are more than 89 different HLA-B51 subtypes, and HLAB5101 is the main sub-allele associated with BS in all populations studied. HLA-B5108 was also found to be associated with BS in Middle Eastern, Italian, Spanish, Greek, Turkish, and German patients. In contrast, it has been suggested that HLA-B5107 might be negatively related to BS in Turkish and German populations. Research on the HLA-B5101 gene from Japanese, Turkish, Jordanian, and Iranian patients and found that all patients had B510101 showed that susceptibility to BS. The study also found a number of less significant associations, namely a decrease in the frequency of HLA-B35 in patients with thrombophlebitis, an increase in HLAA29 and a decrease in the frequency of HLABw6 in patients with ocular involvement, a decrease in the frequency of HLA-Cw2 in patients with erythema nodosum, and a decrease in HLA-frequency Cw7 in patients with genital ulceration [13].

Pathogenetic role of HLA-B51 in BS has not been widely explained. However, the HLA-B51 molecule itself plays a role in neutrophil hyperfunction in BS. Studies in HLA-B51-transgenic mice have shown an increase in neutrophil function as seen in BS patients. Because the main role of HLA-class HLA antigens such as HLA-B51 is to bring endogenous peptides to CD8 + T cells, the lack of disease phenotype in this mouse model can be explained by the absence of microbes or peptides associated with triggering injuries. activates CD8 + T cells related to disease. MICA (9-mer peptide AAAAAIFVI) is an antigenic peptide that is stress induced and is one of many potential triggers for BS. Genes related to MHC class I (MIC-A) chains are also considered candidates for BS genetic susceptibility. Several studies have shown an association between MIC-A009, MIC-A006, MIC-A6 TM, and BS. However, this association seems to be the result of disequilibrium of the strong association of MIC-A with HLA-B51 [14].

The immune system mediated cytokines play an important role in the pathogenesis of various diseases including BS. Several genes 
such as the IL gene (IL-1A, IL-1B, IL-1 receptor antagonist, IL-2, IL-6, IL-10, IL-12B promoter, IL-17F gene, IL-18, IL-23R), tumor necrosis factor (TNF) genes, transporters associated with antigen processing genes (TAP), intermolecular adhesion genes (ICAM1), endothelium nitric oxide synthase (eNOS) genes, glutathione S-transferase, N-acetyltransferase genes and polymorphisms of vascular endothelial growth factor genes (VEGF) have been linked to BS susceptibility. The correlation between polymorphism and platelet glycoprotein Ia C807T/G873A platelet gene in BS and we found that the risk of thrombosis was significantly higher in patients who had 807TT and 807CT. The association of factor $\mathrm{V}$ Leiden and prothrombin gene mutations with BS was confirmed in several studies $[10,11]$.

\section{Conclusion}

Comprehensive analysis of the effect of the HLA-B51/B5 allele on the risk of developing BS further illustrates the relationship of this disease gene as one of the most potential. Future research should reveal the potential interactions of these alleles with other genetic and nongenetic BS and risk factors and with the BS phenotype.

\section{Conflict of Interest}

None.

\section{Bibliography}

1. Calamia KT., et al. "Major vessel involvement in Behcet's disease: an update". Current Opinion in Rheumatology 23.1 (2011): 24-31.

2. Saadoun D and Wechsler B. "Behçet's disease". Orphanet Journal of Rare Diseases 7 (2012): 20.

3. Saadoun D., et al. "Mortality in Behcet's disease". Arthritis and Rheumatology 62.9 (2010): 2806-2812.

4. Saadoun D., et al. "Ocular manifestations of Behcet's disease". Revue de Médecine Interne 31.8 (2010): 545-550.

5. de Chambrun MP., et al. "New insights into the pathogenesis of Behcet's disease”. Autoimmunity Reviews 11.10 (2011): 687698.

6. Geri G., et al. "Critical role of IL-21 in modulating TH17 and regulatory $\mathrm{T}$ cells in Behcet disease". Journal of Allergy and Clinical Immunology 128.3 (2011): 655-664.

7. Kaya T İ. "Genetics of Behçet's Disease". Pathology Research International (2012): 912589.
8. Piga M and Mathieu A. "Genetic susceptibility to Behçet's disease: role of genes belonging to the MHC region". Rheumatology 50.2 (2011): 299-310.

9. Kaya TI., et al. "Association of class I HLA antigens with the clinical manifestations of Turkish patients with Behçet's disease". Clinical and Experimental Dermatology 27.6 (2002): 498-501.

10. Ferizi M., et al. "Behçet's Disease - Case Presentation and Review Literature". Open Access Macedonian Journal of Medical Sciences 6.10 (2018): 1871-1874.

11. Marinho KC., et al. "Behçet's syndrome: Literature review and clinical case reportSíndrome de Behçet: Revisión de la literatura y presentación de Caso Clínico". Revista Española de Cirugía Oral y Maxilofacial 38.2 (2016): 105-110.

12. Zeidan MJ., et al. "Behçet's disease physiopathology: a contemporary review". Autoimmunity Highlights 7.1 (2016): 4.

13. de Menthon M., et al. "HLA-B51/B5 and the risk of Behçet's disease: a systematic review and meta-analysis of case-control genetic association studies". Arthritis and Rheumatology 61.10 (2009): 1287-1296.

14. Esatoglu SN., et al. "Behçet's syndrome: providing integrated care". Journal of Multidisciplinary Healthcare 10 (2017): 309319.

\section{Assets from publication with us}

- Prompt Acknowledgement after receiving the article

- Thorough Double blinded peer review

- Rapid Publication

- Issue of Publication Certificate

- High visibility of your Published work

Website: www.actascientific.com/

Submit Article: www.actascientific.com/submission.php Email us: editor@actascientific.com

Contact us: +919182824667 